\title{
MUNDO ESCOLAR E LITERATURA EM LOUIS PERGAUD
}

\author{
WORLD SCHOOL AND LITERATURE IN LOUIS PERGAUD \\ MUNDO ESCOLAR Y LITERATURA EN LOUIS PERGAUD
}

Michel Thiollent*

Doutor em Sociologia. Université Rene Descartes, Paris V, Sorbonne, UER | França E-mail: m.thiollent@gmail.com

\begin{abstract}
REVISTA PEDAGÓGICA
Revista do Programa de Pós-graduação em Educação da Unochapecó | ISSN 1984-1566

Universidade Comunitária da Região de Chapecó | Chapecó-SC, Brasil Como referenciar este artigo: THIOLLENT, Michel. Mundo escolar e literatura em Louis Pergaud. Revista Pedagógica, Chapecó, v.16, n.32, p. 17-31, Jan./Jul. 2014.
\end{abstract}

\begin{abstract}
RESUMO: Levando em conta uma leitura de obras literárias de Louis Pergaud (1882-1915), correspondências e informações sobre sua biografia, procura-se encontrar sinais da posição crítica do autor, que havia sido professor de ensino primário na região do Jura (França), sobre a educação pública e a pedagogia impositiva de sua época. Tal posição o levou a deixar o mundo escolar de província para tentar a fama literária em Paris no início do século XX. Podendo ser qualificada de libertária, não dogmática, sua posição se expressa principalmente em sua obra mais conhecida, A Guerra dos Botões, e em suas conferências e correspondências. Revela-se uma crítica à concepção do ensino, à pedagogia e aos valores do modelo de escola que estava sendo implantado. Convocado como soldado para a guerra em 1914, Louis Pergaud morreu em combate em 1915, deixando sua obra inacabada
\end{abstract}

PALAVRAS-CHAVE: Escola pública. Pedagogia. Literatura. França. Valores.

\begin{abstract}
Taking into account a reading of literary works of Louis Pergaud (1882-1915), correspondence, and information about his biography, we seek to find signs of the critical position of the author, who had been a professor of primary education in the Jura region (France), on public education and prescriptive pedagogy of his time. This position led him to leave school world of province to try literary fame in Paris in the early twentieth century. Described as libertarian, non-dogmatic, his position is expressed mainly in his most famous work The War of the Buttons and in conferences and correspondence. The author presents a critique of the conception of education, pedagogy and values of the school model that was being deployed. Drafted as a soldier to war in 1914, Louis Pergaud died in combat in 1915, leaving his work unfinished.
\end{abstract}

KEYWORDS: Public School. Pedagogy. Literature. France. Values. 
* Professor Adjunto do PPGA/Programa de Pós-Graduação em Administração da UNIGRANRIO e professor aposentado da Coppe/UFRJ
A memória aniquila o tempo: conduz à unidade aquilo que parece ter acontecido em separado. (Tolstói, L. 2011, p. 391).

\section{INTRODUÇÃO}

Nossa proposta consiste em um exercício de memória, documentado com base em obras literárias de Louis Pergaud (1882-1915) e de alguns de seus contemporâneos, descrevendo de modo retrospectivo aspectos da vida em escolas públicas no interior da França no final do século XIX e início do século XX, período marcado por um clima de patriotismo, prelúdio para a "Grande Guerra" e seus horrores. A obra mais conhecida - A Guerra dos Botões traz recordações do autor sobre a vida de crianças e professores e a pedagogia em uso nas escolas primárias daquela época.A postura crítica do autor quanto a essa pedagogia levou-o a abandonar a educação para entrar no mundo das letras. Nessa viagem no tempo, apesar de tantas mudanças ocorridas, sugere-se que a pedagogia tradicional, impositiva, que continuou em vigor nas escolas ao longo do século $\mathrm{XX}$, cria constrangimento e desinteresse tanto por parte dos professores como dos alunos, situação de que certas pessoas pretendem escapar ou fugir. Sem dúvida, trata-se de uma postura apenas subjetiva ou pessoal e que se desdobra, no caso peculiar, em apego pela literatura e artes. Não se deve transformar tal subjetividade em determinação sociológica, ou interpretá-la como fato que sempre se repete.

\section{CONTEXTO}

Na França, o final do século XIX e início do século XX correspondem ao período de implantação do modelo republicano de escola primária, com separação do Estado e da Igreja. Foi um período bastante conturbado devido à reação popular, sobretudo em áreas rurais, marcada pelo conservadorismo político e religioso. Os professores de ensino primário recém-formados das Écoles Normales difundiam a visão republicana. Segundo o escritor Marcel Pagnol, tais escolas "eram, nessa época, verdadeiros seminários, mas nelas, o estudo da teologia era substituído por cursos de anticlericalismo." (Pagnol, 1994, p. 16). Uma vez nomeados em localidades remotas da província, os professores eram vistos como propagadores do ateísmo e sofriam hostilidades por parte da população conservadora local. Muitos deles encontravam problemas de adaptação, isolamento, tédio, incompreensão. Alguns se engajavam na política; outros se refugiavam na poesia ou na observação da natureza e da vida camponesa; outros, ainda, desistiam¹.

O ensino da moral, por meio da leitura de textos escolhidos pelas autoridades, e a instrução cívica, exerciam um importante papel na transmissão de valores (Mertke, 2001). Segundo Julia Mertke:

Em 1881, as escolas primárias públicas tornaram-se gratuitas, obrigatórias e laicas, o que significa que a oração e o catecismo são 
substituídos pela moral e a instrução cívica, no entanto, uma tarde por semana ficava livre para o ensino religioso fora da escola. (Merkte, 2001, p. 3)

Em Foucambert (2010) encontramos também ricas informações sobre o funcionamento do modelo de escola chamada "Escola Jules Ferry", de nome do ministro que o implantou. Nesse contexto, a mentalidade imposta aos professores e alunos das escolas primárias públicas da França foi moldada em um padrão exposto, décadas mais tarde, por Halden (1925) e outros. Isso já foi objeto de estudo com base no manual de leitura do próprio Charles ab der Halden (Thiollent, 2004).

Na vida real, Louis Pergaud viveu uma situação de tédio e imposição moral em Landresse, no Jura, onde havia sido nomeado instituteur (professor de ensino primário) na escola municipal, e onde morou algum tempo, sem se adaptar à cultura local, embora fosse originário daquela região. Começou a observar o entorno imediato: vida animal, caças, caçadores, camponeses, vida das crianças na escola e fora dela, famílias dos alunos. Escreveu contos ambientados no mundo animal (Pergaud, 1940), retomando até certo ponto, de modo mais realista, a tradição das fábulas de Jean de La Fontaine (séc. XVII) e de Esopo, da Grécia antiga. Essas fábulas descrevem comportamentos de animais (lobo, ovelha, corvo, raposa, cão, cervo etc.) com intenções metafóricas, simbólicas ou morais aplicáveis aos humanos. As obras rurais de Pergaud, com "personagens" animais, não se relacionam diretamente com o mundo escolar, embora remetam a observações do professor de ensino primário sobre o entorno camponês da escola.

Em sua Correspondance (publicada em 1965), Louis Pergaud revela, da seguinte maneira, os problemas que encontrava: "Faz quatro meses que estou em Landresse, uma terra ultra-conservadora [ultra-chouan], onde sinto um tédio de morrer, afastado das comunicações (a $18 \mathrm{~km}$ de Valdahon) e que gentalha! [Bon Dieu, quelle populace!]” (1965, p. 28). Ele menciona também: "aborrecimentos com as populações católicas, denúncias, abaixo-assinados me assediam de toda parte". (Pergaud, 1965, p. 32).

As dificuldades do exercício da profissão de professor de ensino primário levaram Pergaud a se desinteressar pela educação e a se dedicar à literatura e à arte poética. A sua vocação de educador perdeu para a de escritor, experiência iniciada em companhia do poeta Léon Deubel (1879-1913). Com a esposa Delphine Duboz, filha de Jules Duboz, comerciante, contador de histórias, ele deixou o mundo escolar das aldeias do Jura e se estabeleceu em Paris, em 1907, para escrever e se relacionar com o meio literário parisiense. Em 1909, ele morou no Quartier Latin, onde conviveu um tempo com o poeta Léon Deubel, doente de tuberculose e que cometeu o suicídio em 1913. 
Pergaud redigiu vários romances e entrou em contato com escritores que o introduziram no mundo das letras, onde conheceu intelectuais de orientação próxima ao anarquismo, como Octave Mirbeau (1848-1917) e Lucien Descaves (1861-1949), influentes no meio editorial e nos sistemas de premiação, que o ajudaram no início da carreira em Paris. Sua opção pela literatura foi rapidamente recompensada pela obtenção do Prêmio Goncourt, em 1910, atribuído ao romance De Goupil à Margot. O autor tinha apenas 28 anos. Em 1912, publicou La guerre des boutons, livro de maior sucesso, reeditado até hoje, e inspirador, bem mais tarde, de vários filmes, tais como os realizados por Jacques Daroy, em 1937, por Yves Robert, em 1962 (com sucesso de bilheteria), e por Yann Samuel, em 2011, em contexto irlandês.

Numa perspectiva próxima à de Louis Pergaud, na mesma época, Alfred Machart (1887-1962) também publicava romances populares narrando conflitos entre crianças nas escolas, só que no contexto urbano de Paris e de seus subúrbios. Os principais títulos de Machart, evocativos, são Les cents gosses (1912) e La guerre des mômes (1916). Mais tarde, esse autor ficaria mais conhecido por sua participação no mundo do cinema como roteirista e diretor de filmes. As especificidades das crianças do campo e das da cidade levaram a uma discussão entre os dois autores. Segundo Pergaud, embora mais isoladas, as crianças do campo não são menos espertas que as das grandes cidades (Pergaud, 1987, 1963).

No período em que permaneceu em Paris, por razões de sustento, Pergaud aceitou um emprego burocrático na Companhia das Águas e também continuou dando aulas em escolas públicas, mas, perdendo gosto pela educação, ele assim se lamentou: "É em Maisons-Alfort [cidade da periferia ao sul de Paris] que eu trabalho agora, com 75 crianças [gosses] que nem sabem juntar duas letras!" (Pergaud, 1965, p. 64).

Migrar do mundo da educação, como toda riqueza de vivências, para o mundo literário é um caminho, por vezes arriscado, que diversos educadores insatisfeitos têm iniciado. Os motivos dessa insatisfação com a escola e da atração para o mundo das artes poderiam ser objeto de reflexão. Há um aspecto de biografia individual que não se pode generalizar, mas há também uma dimensão sociológica. De fato, o mundo literário podia ser uma porta aberta a novos horizontes de criação, fora da rotina escolar. Entretanto, para quem vinha do campo, podia ser também arriscado e desconfortável. Bourdieu, em seus estudos sobre o campo literário, embora não tivesse comentado especificamente sobre a situação de Pergaud, dá o exemplo de outro escritor - Léon Cladel (1835-1892) - também originário de uma região rural (o Quercy) e de família de baixo capital social, econômico e cultural, que tentou entrar no campo 
intelectual e literário parisiense. Vivendo no entremeio de dois referenciais culturais, tal escritor encontrou grandes dificuldades de inserção, apesar de ter publicado um livro prefaciado por Charles Baudelaire (Bourdieu, 1992, p. 363370). No caso de Pergaud, é provável que o mesmo tipo de problema não tenha se desenvolvido pelo fato de a guerra ter abreviado sua vida. Todavia, sua posteridade permaneceu prejudicada no campo literário dominante que não deixava desabrochar obras de autores provenientes do campo, vistos como provincianos ou de menor relevância na hierarquia cultural do sistema oficial.

\section{UMA PEDAGOGIA DISTANTE DA VIDA COTI- DIANA}

Ainda que de orientação republicana, Louis Pergaud ironizava a pedagogia do sistema escolar posto em funcionamento no final do século XIX pela III República.

Naquele momento o ensino primário não era visto como educação de base, mas como instrução rígida. Tratava-se de formar cidadãos que pudessem ler, escrever e contar, e que tivessem uma instrução cívica e moral compatível com o espírito republicano, além de uma preparação patriótica adequada para as guerras (Chanet, 2001). No contexto histórico do início do século XX, essas guerras eram previsíveis, em particular no que diz respeito às relações franco-prussianas e a ocupações coloniais. Além das escolas, o serviço militar propiciava a continuação normal da mesma mentalidade para os jovens.

No ensino de escola primária, a História de França era uma matéria importante, mas ensinada de modo linear, como sucessão de reis e personagens importantes e de datas de batalhas; as vitórias davam orgulho e as derrotas deixavam um sentimento de tristeza e eram pouco comentadas. Nesse retrospecto, havia vieses interpretativos em função de ideais patrióticos e de interesses políticos republicanos, anticlericais, ou geopolíticos.

Em seu livro mais conhecido, "A Guerra dos Botões”, Pergaud descreve a vida escolar em Landresse, vilarejo situado a $54 \mathrm{~km}$ de Besançon, que é o verdadeiro nome de Longevergne, onde ocorriam os fatos narrados no romance. Meninos de Longevergne rivalizavam com os de Velrans, vilarejo vizinho. Um dos aspectos dessa rivalidade remetia ao conflito entre famílias de ideologias republicana e monarquista (Mertke, 2001, p.3).

A narrativa de Pergaud possui pressupostos críticos quanto ao funcionamento das escolas públicas, ao papel dos professores, às características culturais de alunos em regiões rurais da província de Franche-Comté. Querer mostrar isso de modo exaustivo no conjunto dos textos do autor seria uma tarefa desproporcionada com o objetivo do presente estudo. Só para ilustrar, de modo bastante imediato, recorramos a um trecho de "A Guerra dos Botões": 
Como todos os seus colegas, Lebrac [nome de um aluno rebelde] estava certo de ter copiado; evidentemente ninguém duvidava disto, inútil discutir. Mas o que se queria era saber se ele tirara algum proveito do exercício banido em princípio dos métodos da pedagogia moderna. (Pergaud, 1995, p. 30)

No currículo obrigatório, entre outros itens de conteúdo prático e técnico, havia o sistema métrico, motivo de orgulho nacional. Os alunos precisavam saber converter mentalmente medidas representadas em metros, decímetros, centímetros, milímetros, hectômetros, quilômetros, e, também, medidas em litros, decilitros, centilitros, mililitros, decalitros, hectolitros etc. Por vezes era difícil entender as superfícies com elevação ao quadrado de uma distância e os volumes com elevação ao cubo. A maior dificuldade é que esse sistema não fazia parte do quotidiano: ainda existiam, nas províncias, outros sistemas de medição de origem medieval.

Nos próprios termos de Pergaud (1995, p. 31):

Por isso, Lebrac e os outros [...] escutaram naquele dia, com uma atenção concentrada, as palavras do professor, que expunha furioso os abusos dos antigos sistemas de pesos e medidas e a necessidade de um sistema único.” O autor nota também que vários alunos "juraram para si próprios [...] que, para se lembrar desta terrível mixórdia, prefeririam medir sempre com pés e polegadas, como haviam feito seus pais e avós [...] de que empregar esse maldito sistema, que quase os fizera passar por culhões aos olhos de seus inimigos (Pergaud, 1995, p. 32).

Como bem observaram Catani e Gilioli:

[...] aparece a cultura escolar formalista como oposta ao rico universo de representações da criança. Durante as aulas e no período escolar, as crianças não estavam interessadas em apropriarem-se de conhecimentos que falavam a respeito de um sistema métrico do qual não se utilizavam ou da conceituação do que é o cidadão - que para início de conversa, era $\mathrm{o}$ adulto. (Catani; Gilioli, 2004, p. 113).

A incompreensão e a insatisfação dos alunos se manifestavam por meio de chahut (desordem) e indisciplina nas aulas ou no pátio da escola durante o recreio. As punições eram frequentes. Na saída, havia confusões e brigas entre grupos de alunos, mas por motivos mais complexos, relacionados com diferenças entre locais de moradia nos arredores, condição social ou influência religiosa (conflito entre crianças oriundas de famílias católicas e protestantes. Embora não explicitado, esse conflito estava no centro do romance "A Guerra dos Botões").

Nas escolas públicas recém-criadas, prevalecia uma pedagogia prescritiva, impositiva, com a qual não se reco- 
nhece a variedade da cultura e da linguagem dos alunos, variedade relativa às especificidades locais e sociais (condições de classe e religiões), nem a possibilidade de terem interesses ou expectativas específicos. Faltava uma relação estreita entre o mundo dos livros e a vida cotidiana ou o entorno cultural. Todo o conteúdo de ensino devia ser único e padronizado, independentemente das regiões ou dos grupos sociais, conforme o ideal republicano, universalizante e homogeneizante por princípio.

O caráter impositivo da instrução pública é bem conhecido e era teoricamente justificado por intelectuais, como Émile Durkheim, por exemplo, que sempre insistiu sobre a necessidade de conformar os alunos à disciplina, aos conteúdos preestabelecidos, às normas escolares e a demais exigências da sociedade e de suas instituições. (Durkheim, 1995; 2013).

A concepção do ensino primário carregava a visão do racionalismo/iluminismo herdada do século XVIII. Era a ideia "cara aos homens da Revolução Francesa, de uma deusa razão iluminando o caminho da humanidade, dissipando as trevas da ignorância, os fantasmas da superstição religiosa ou as ilusões do sentimento" (Vernant, 2009, p. 1923).

Em contraposição, naquela época, em perspectiva crítica e libertária, Elisée Reclus, geógrafo, apontava em 1905 a relatividade das verdades ensinadas: "Os professores, simples gente de ofício, não são necessariamente animados por esse fogo sagrado que é o entusiasmo pelo verdadeiro, e o que eles ensinam na maioria das vezes é só uma lição ditada em conformidade com interesses de nacionalidade, religião, casta." (Reclus, 2010, p. 10)

Embora não tenha escrito muito sobre a questão, Louis Pergaud criticou a pedagogia oficial de modo contundente. Numa conferência proferida em Paris, em 18 de fevereiro de 1914, ele declarou:

A pedagogia que eu tenho praticado após ter sido submetido a ela é provavelmente uma boa ciência, mas não conheço nenhuma outra que seja mais vã, mais vazia e mais inútil. Todos os métodos são, perdoem-me usar a palavra, bobagens; eu não posso dizer que em se tratando de um aluno inteligente, certos métodos sejam bons e em se tratando de um mau aluno, esses mesmos métodos sejam ruins... até que encontremos o método certo.

O único resultado significativo a que se chega é tornar a criança hipócrita e dissimulada, o que, aliás, não é de se lamentar, já que é uma atitude necessária e até indispensável para o bom funcionamento da vida social.

Muitas vezes, mesmo entre os meninos bem comportados, esta atitude é tomada incons- 
cientemente, de modo natural: é um tipo de fenômeno que se poderia qualificar de mimetismo moral, com o qual o sujeito adota a linguagem e a conduta do ambiente em que se encontra. A criança sabe que em casa, na escola, na igreja, entre os vizinhos, certa maneira de agir é necessária, que certa linguagem é a regra, à qual é preciso se conformar, mas uma vez sozinho ou com seus pares, ele volta a se mostrar como verdadeiramente é, com seus desejos ardentes, suas prementes necessidades e sua impetuosa atividade. (Pergaud, 1963, p. 167, grifos nossos).

Segundo uma crítica assumida por Pergaud, o ensino primário tal como era praticado levava a uma aprendizagem da hipocrisia e dissimulação. De longa data, em outros contextos históricos, esse tipo de crítica já havia sido expressado por Rabelais no século XVI, La Bruyère no século XVII, Voltaire no século XVIII entre outros.

A crítica que Pergaud faz não se apresenta como crítica teórica ou sistematizada em função de alguma doutrina pedagógica preestabelecida. Mesmo sendo ideologicamente inclinado para uma visão anarquista, ele não se refere a ideias pedagógicas de autores especificamente libertários, conhecidos e muitas vezes contestados por causa da autonomia que davam aos alunos no decorrer do aprendizado destes. A crítica aparece nas entrelinhas e está associada à adoção de um estilo literário sarcástico, irônico, alegórico, por vezes cômico, inspirado em Rabelais, influência reconhecida explicitamente por uma citação em destaque no início do primeiro capítulo. Corrêa comenta que "Pergaud tinha François Rabelais (1494-1553), escritor desbocado e brincalhão que criticava os hipócritas, como seu grande ídolo e que, como este, escrevia numa linguagem muito popular, com um humor escrachado." (Corrêa, 2002, p. 122). Esse tipo de atitude remete a certo ceticismo quanto aos valores transmitidos pelo sistema escolar da época, em condições inadequadas aos hábitos e expectativas culturais da população e das crianças, em particular no contexto rural.

Todavia, a postura de Pergaud não parece oferecer solução aos problemas da educação; ele prefere uma crítica satírica e não parece promover pedagogias alternativas, ou pedagogias centradas na liberdade do aluno, que, à época, podiam se inspirar em Rousseau, Pestalozzi, Tolstói e, também, em vários pensadores anarquistas.

\section{INFLUÊNCIAS INTELECTUAIS}

Pergaud se referiu ao estilo de Rabelais quando escreveu "A Guerra dos Botões" para indicar aspectos satíricos, irônicos, sarcásticos, irreverentes ou cômicos relacionados com as situações descritas. Vale o exemplo dos exageros das personagens Gangantua e Pantagruel, na transição entre Idade Média e Renascimento, para se zombar da ordem 
estabelecida e das autoridades políticas e eclesiásticas daqueles tempos.

Para criticar a escolástica do ensino nas escolas de seu tempo, Pergaud se inspirou em Rabelais, que ironizava a escolástica medieval. Segundo Vieira, Rabelais escreve que por vontade de seu pai Grandgousier, "Gargantua é destinado a uma boa educação nas mãos de grandes doutores sofistas, que o recheiam de sabedoria escolástica, a qual ele levava muitos anos para assimilar, tornando-se ao final 'idiota, palerma, distraído e bobo'." (Vieira, 1986, p. 15). Os sofistas eram também chamados de teólogos (Rabelais, 1942, p. 69) ou de "sorbonistas" nas primeiras edições da obra (Bakhtin, 2010, p. 187).

Outra referência a Rabelais diz respeito à visão das guerras. As guerras picrocolinas narradas por Rabelais (1991, p. 393-94), exemplos de guerras irrisórias, ridículas, desencadeadas entre reis por motivos mesquinhos, também são referenciadas por Pergaud para salientar o absurdo dos conflitos e das guerras de vários tipos, inclusive guerras entre grupos de alunos das escolas e, mais tarde, guerras entre adultos, como no caso da "Grande Guerra".

Pelo fato de Pergaud ter encontrado em Rabelais um estilo de escrita, talvez seja possível mostrar alguns aspectos de suas obras à luz do que Bakhtin comentava sobre a cultura popular do século XVI, com expressões cômicas e por vezes grosseiras. Bakhtin (1987, p. 2) considerava que: "As imagens de Rabelais se distinguem por uma espécie de 'caráter não-oficial', indestrutível e categórico, de tal modo que não há dogmatismo, autoridade nem formalidade unilateral [...].” Das imagens utilizadas nos romances de Pergaud, poder-se-ia dizer o mesmo. Ele descreve o lado não oficial da escola pública, ou da vida dos camponeses, com muitas anedotas que sugerem ao leitor uma visão não dogmática da educação e da vida social.

No início do século XX, em cartas que escrevia a amigos ou personalidades das áreas de educação e de literatura, Louis Pergaud revelava sua postura republicana, materialista e anticlerical; detalhes são encontrados na Correspondance (Pergaud, 1965). Embora não tivesse militância ou engajamento explícito, ele manifestava simpatia para com a visão socialista e anarquista. Não havia referência ao marxismo, ainda pouco difundido na França naquele momento.

Pergaud admirava Maurice Boucher (1855-1929), romancista e poeta, autor de obras como Le pain e La muse et l'ouvrier, próximo ao anarquismo. Na região de Franche-Comté, Louis Pergaud manifestou viva admiração por Édouard Droz (1853-1923), influente professor da Faculdade de Letras de Besançon, autor de vários romances, também simpatizante do anarquismo, e que escreveu em 1909 um livro de homenagem a Pierre-Joseph Proudhon (1809-1865) na ocasião do centenário do nascimento deste 
intelectual libertário, que viveu em Besançon e que, mesmo desaparecido, ainda exercia ampla influência.

Louis Pergaud revela sua simpatia pelo socialismo e sua posição anticlerical quando escreve a Eugène Chatot, em 23 de junho de 1901, que:

conta com o apoio de seus colegas de promoção dedicados à 'obra social' [...] Eu conto com eles para dar uma boa impulsão à Escola da Democracia, porque, sob a antiga, tirânica e clerical dominação de Tronchon, a Escola era apenas 'jésuitière'. O novo Diretor (E. Rouget) é muito diferente; é amigo de Droz e, consequentemente, ele deve, pelo menos em parte, compartilhar suas opiniões (PERGAUD, 1965, p. 16).

Em carta de 04 de janeiro de 1904, Pergaud declara a Rouget que: "recentemente, eu quebrei a cabeça deliciosamente lendo o Zaratustra de Nietzsche e eu me deliciei lendo páginas de Anatole France em Lysrouge, Monsieur Bergeret à Paris e Le livre de mon ami." (idem, p. 23). O poeta François Villon (1431-1463), com sua notória irreverência ou rebeldia, também foi evocado como exemplo para Pergaud: "Eu conheço tanto quanto é possível a vida de Villon e tenho tentado revivê-la em um poema de sessenta versos". (idem, p .23).

Em 23 de maio de 1905, Pergaud escreveu uma carta a E. Rouget, Diretor da École Normale de Besançon, em que indica que ele estava relendo as obras completas de Victor Hugo e declara sua intenção de ler obras de Guyau, como L'irreligion de l'avenir (1886), Vers d'unphilosophe (1881), perguntando onde ele poderia encontrar esses livros (Pergaud, 1965, p. 19). Lembra-se que Jean-Marie Guyau (1854-1888), filósofo, pedagogo e poeta, elogiado por F. Nietzsche e P. Kropotkin por sua teoria da sanção (Guyau, 1885, 2013), exercia forte influência na fundamentação moral, pedagógica e anticlerical da escola republicana da época. Na mesma carta, Pergaud revela também seu interesse em estudar com maior profundidade as obras de Renan e Flaubert.

Apesar de ser pacifista e antimilitarista, Louis Pergaud foi à guerra em agosto 1914 para lutar contra o Kaiser (Chikoff, 2013), mas perdeu a vida nas trincheiras em Marchéville-en-Woëvre, nas proximidades de Verdun e das fronteiras belga e alemã, em 8 de abril de 1915. No conjunto de sua obra, seria possível ver a primeira guerra, a das crianças, como metáfora da segunda, a dos adultos, de maiores proporções. O absurdo das cenas do início da guerra de 1914 é relatado no Carnet de Guerre (Pergaud, 2011) e em trechos apresentados em Piccoli (2006). Por vezes, a realidade e a ficção se encontram. Em dias de relativa calmaria entre dois bombardeios, o soldado Pergaud anotou na sua caderneta que no meio das trincheiras ou dos abrigos onde se encontrava, ele lera trechos de seus li- 
vros para os companheiros de combate. Em 17 de fevereiro de 1915, Pergaud notou no seu diário que ele fez alusão à "Guerra dos Botões" em conversas "ousadas" com os camaradas, que ficaram entusiasmados (Piccoli, 2006, p. 279).

Não sabemos até que ponto Pergaud teve acesso à leitura de obras pedagógicas da linha libertária ou emancipatória, como as de Rousseau ou Tolstói. Por tradição, os professores primários da época, formados na École Normale, adquiriam uma visão fortemente influenciada pelo positivismo e pelo espírito republicano. Entretanto, segundo Duchesnay (1972), na biblioteca da casa onde Pergaud morava, em Landresse, foram encontrados livros de grandes nomes da literatura e poesia francesas, como La Fontaine, La Bruyère, Rabelais, Victor Hugo, Verlaine, Mallarmé e Baudelaire. Sem dúvida, são autores distantes do ideário positivista.

À margem desta questão, na história das ideias pedagógicas, a liberdade e a autonomia do aluno têm sido associadas ao pensamento de Jean-Jacques Rousseau (1712-1778). Sua concepção exposta na obra intitulada Emílio, apesar de ter sido objeto de críticas, simplificações e distorções, inspirou pedagogos como Tolstói e até Paulo Freire. Isaiah Berlin observou que Tolstói "permaneceu admirador de Rousseau e, avançando em anos, ainda recomendava Emílio como melhor livro jamais escrito sobre a educação” (Berlin, 1988, p. 69). Para Liev Tolstói (apud Lipianski, 1999, p. 30), “o único critério da pedagogia é a liberdade, o único método, a experiência”. Em suas palavras: "Uma criança, ou um adulto, só aprende quando sente gosto pelo objeto de estudo. Sem isso ocorre um dano, um terrível dano intelectual, que transforma as pessoas em deficientes mentais" (Tolstói, 2011, p. 213). Sabe-se também que Tolstói (2005) escreveu contos e histórias em linguagem simples, adequada para a aprendizagem da leitura entre crianças do campo.

De certo modo, considera-se que, em outro contexto e na segunda metade do século XX, com perspectiva pedagógica mais crítica e engajada, Paulo Freire deu continuidade ao mesmo tema: o da íntima relação da educação com a vida, recusando-se a ensinar com frases artificiosas, como "Eva viu a uva", utilizadas em pedagogia de alfabetização tradicional. Nesse sentido, Moacyr Gadotti enfatiza: "Aprendemos com a própria vida, ensinou Paulo Freire" [...] "Como diz Rousseau (em seu livro Profissão de Fé do Vigário de Saboia) tudo o que aprendi foi pela 'inspeção do universo' ... pela 'leitura do mundo' diria Paulo Freire." (Gadotti, 2004, p. 19)

De forma romanceada, em um sentido compatível com essa perspectiva, Pergaud já criticava a falta de vínculo do conteúdo do ensino fundamental com o contexto de vida dos alunos. Essa crítica foi expressa em uma linguagem popular inspirada em Rabelais. Não pretendemos aqui 
aprofundar a questão de possíveis semelhanças da postura de Pergaud com posições críticas acerca do mundo escolar atual, pois a distância no tempo e no espaço é muito grande e haveria riscos de exageros interpretativos.

\section{CONCLUSÃO}

Louis Pergaud teve uma postura crítica com relação à pedagogia (conteúdo e métodos) do ensino na escola primária - pública, gratuita, laica - em fase de implantação na França no final do século XIX e início o século XX. Tal pedagogia, convencional e imposta, incitava o aluno à hipocrisia e à dissimulação. Sem espírito crítico, a "instrução pública" formava os jovens em uma perspectiva patriótica, preparando-os para a guerra.

No entanto, Pergaud não sugeriu nenhuma alternativa, que, de acordo com a lógica de tal postura, poderia ter sido de tipo libertário. É possível interpretar essa ausência de alternativa como resultado do desespero diante da forte reação popular e religiosa que existia contra a escola da República separada da Igreja Católica. Nas províncias francesas, em muitos vilarejos e cidadezinhas, essa reação infernizava a vida dos professores das escolas primárias. O autor acabou se desinteressando do ofício de professor interiorano e, por gosto pessoal, começou a se consagrar à literatura (romance e poesia), o que o afastou do magistério e o levou a Paris, onde se aproximou do meio literário e libertário, antes de ser convocado para a guerra e morrer em combate. Sua vida foi curta demais para que o autor chegasse a obras de maturidade, ou mais ambiciosas.

As crianças de famílias camponesas tinham uma linguagem popular distante da norma escolar, e os conteúdos de ensino, influenciados pelo positivismo do século XIX, também estavam distantes do dia a dia, impostos sem que se levassem em conta as condições de vida e as culturas locais. Fazendo-se abstração das circunstâncias peculiares de cada época, deixando, segundo a expressão, a "memória aniquilar o tempo", considera-se que o problema continua mal resolvido até hoje, o que justifica a importância a ser atribuída à educação centrada no diálogo entre saberes diferenciados, eruditos e populares.

\section{REFERÊNCIAS}

AB DER HALDEN, Charles. Leçons de morale. Paris: Armand Colin, 1925 .

BAKHTIN, Mikhail. A cultura popular na Idade Média e no Renascimento: o contexto de François Rabelais. Tradução: Yara Frateschi Vieira. 7.ed. São Paulo: HUCITEC; Brasília: Editora da Universidade de Brasília, 2010.

BERLIN, Isaiah. Pensadores russos. São Paulo: Companhia das Letras, 1988. 
BOURDIEU, Pierre. Les règles de l'art. Genèse et structure du champ littéraire. Paris: Seuil, 1992. [Trad. bras.: As Regras da Arte. São Paulo: Companhia das Letras, 2002]

CATANI, Afrânio Mendes; GILIOLI, Renato de Souza Porto. Cinema, escola e representações da infância em A Guerra dos Botões (1961). In: SETTON, Maria da Graça Jacintho (org.). A cultura da mídia na escola. Ensaios sobre cinema e educação. São Paulo: Annablume; USP, 2004. p. 111-120.

CHANET, J.-F. Pour la Patrie, par l'École ou par l'Épée? L'école face au tournant nationaliste. Mil neuf cent, Paris, v. 1, n. 19, p. 127-144, 2001.

CHIKOFF, Irina de. La guerre n'est pas un jeu d'enfants. Le Figaro, Hors-Série, Paris, jun. p. 30-31, 2013.

CORRÊA, Hércules Toledo. Tempos e Espaços Culturais. Diferenças na produção e feitos sobre a recepção (Estudos sobre Indez e a Guerra dos Botões). Tese de Doutorado. Belo Horizonte: Faculdade de Educação da UFMG, 2002.

DUCHESNAY, Guy. Inventaire de la Bibliothèque de Louis Pergaud à Landresse (vers 1906-1907). Les Amis de Louis Pergaud. Bulletin, n. 8, p. 25-29, 1972.

DURKHEIM, Émile. Educação Moral. Petrópolis: Vozes, 2013.

DURKHEIM, Émile. A evolução pedagógica. Porto Alegre: Artmed, 1995.

FOUCAMBERT, Jean. A Escola de Jules Ferry. Um mito que perdura. Curitiba: Editora UFPR, 2010.

GADOTTI, Moacyr. Os mestres de Rousseau. São Paulo: Cortez, 2004.

GUYAU, Jean-Marie.Crítica da Ideia de Sanção. São Paulo: Martins Fontes, 2013.

GUYAU, Jean-Marie. L'irreligion de l'avenir. Étude sociologique. Paris: Félix Alcan, 1886. [Trad.esp. La Irreligióndel Por venir. Estudio Sociológico. Buenos Aires: Americalee, 1947.]

GUYAU, Jean-Marie. Vers d'un philosophe. Paris: G. Baillière, 1881.

GUYAU, Jean-Marie. Esquisse d'une morale sans obligation ni sanction. Paris: Félix Alcan, 1885. [Ensaio de uma moral sem obrigação nem sanção. Lisboa: Guimarães\& Cia, 1919].

LIPIANSKI, Edmond-Marc. A pedagogia libertária. Trad. Plínio Augusto Coelho. São Paulo: Imaginário; NuSol, 1999. 
MACHART, Alfred. Les cent gosses. Paris: Mercure de France, 1912.

MACHART, Alfred. La guerre des faubourgs. Paris: Flammarion, 1916.

MERTKE, Julia. Louis Pergaud: La guerre des boutons Le livre et les valeurs transmises.Saarbrücken: Grin, Universität des Saarlendes, Studienarbeit. 2001.

MUEL, Francine. Les instituteurs, les paysans et l'ordre républicain. Actes de la recherche en sciences sociales. Paris, $n^{\circ} 17-18$, p. 37-61, 1977.

MUEL-DREYFUS, Francine. Le métier d'éducateur. Paris: Minuit, 1983.

PAGNOL, Marcel. A Glória de Meu Pai. Campinas: Pontes, 1994.

PERGAUD, Louis. Carnet de guerre. Paris: Le Mercure de France, 2011. [Édition établie par Françoise Maury. Suivi d>un tombeau pour Louis Pergaud, par Jean-Pierre Ferrini].

PERGAUD, Louis. Aguerra dos botões. Tradução: Geraldo Galvão Ferraz. São Paulo: Ática, 1995.

PERGAUD, Louis. A guerra dos botões. Tradução e adaptação de Cecília Casas. 3.ed. São Paulo: Ediouro, 1994.

PERGAUD, Louis. Correspondance. Paris: Martinsart, 1965.

PERGAUD, Louis. Drames des champs et des bois. Paris: Nelson, 1940.

PERGAUD, Louis. La guerre des boutons. Roman de ma douzième année. Paris: Folio-Plus, 2006. [Contém : Dossier - Le texte en perspective, de Pascale Saliner, p. 305-372].

PERGAUD, Louis. Les petits gars des champs (Conférence 18-02-1914). In : PERGAUD, Louis. Oeuvres complètes. Paris: Mercure de France, 1987. p. 809-825.

PERGAUD, Louis. Les rustiques. Paris: Martinsart, 1963. PERGAUD, Louis. Oeuvres complètes. Paris: Mercure de France, 1987.

PICCOLI, Bernard. Les tranchées de Louis Pergaud. Verdun: Connaissance de la Meuse, 2006.

RABELAIS, François. Gargantua e Pantagruel. Trad. David Jardim Júnior. Belo Horizonte; Rio de Janeiro: Villa Rica, 1991.

RABELAIS, François. Oeuvres complètes. Paris: La Pléiade-NRF, 1942. 
RECLUS, Élisée. O Homem e a Terra. Educação. São Paulo: Imaginário; Expressão e Arte, 2010.

ROUSSEAU, Jean-Jacques. Emílio ou Da Educação. Trad. Roberto L. Ferreira. São Paulo: Martins Fontes, 2004.

THIOLLENT, M. Releitura de um livro escolar de Charles ab der Halden. Pro-posições. Revista quadrimestral da Faculdade de Educação da Unicamp, Campinas, v. 15, n.3, p. 173-194, 2004.

TOLSTÓI, L.N. Contos da nova cartilha. Cotia, SP: Ateliê, 2005.

TOLSTÓI, L.N. La liberté à l'école. Trad. Tseytline e E. Jaubert. Paris: Albert Savine, 1888.

TOLSTÓI, L.N. Obras Pedagógicas. Trad. J.M. Milhazes Pontes. Moscou: Edições Progresso, 1988.

TOLSTÓI, Liev. Carta sobre a Educação (1902). In: TOLSTÓI, Liev. Os Últimos Dias. São Paulo: Penguin Classics - Companhia das Letras, 2011.

VERNANT, Jean-Pierre. Oeuvres II. Religion, Rationalité, Politique. Paris: Seuil, 2009.

VIEIRA, Yara Frateschi. Introdução. In: RABELAIS, François. Gargantua. São Paulo: Hucitec, 1986, p. 11-32.

VILLON, François. Balada dos Enforcados e Outros Poemas. Edição bilíngue. São Paulo: Hedra, 2008. 